\title{
The Link Of Epstein Barr Virus Infection And Rheumatoid Arthritis Immunopathogenesis
}

\author{
Huriatul Masdar
}

\begin{abstract}
The cause of Rheumatoid Arthritis (RA) remains unknown. Environmental factors as well as genetic factors have been linked to pathogenesis of RA, in particular Epstein Barr Virus (EBV) infection. Since clinical onset of RA is long time after primary viral exposure, it is still difficult to demonstrate the direct link of EBV infection with RA pathogenesis. However, the high levels of antibodies against several EBV proteins detected in RA patient sera, the molecular mimicry of EBV proteins with RA susceptible alleles, cross reactive of several antibodies against EBV with proteins in RA synovium, the higher load of EBV in peripheral blood and synovial tissue of RA patients compared to non-RA patients and EBV capability to induce ACPA production might show a clear link of EBV infection with RA pathogenesis.
\end{abstract}

Keywords: rheumatoid arthritis, Epstein Barr virus, immunopathogenesis

Rheumatoid arthritis (RA) is a symmetric and chronic inflammatory peripheral joint disease which is mostly found in the small diarthrodial joints of the hands and feet. ${ }^{1}$ Certain types of HLA-DR class II alleles such as HLA-DRB $1 * 01$ and HLADRB $1 * 0401$ are related to the higher risk of RA susceptibility. ${ }^{2}$ Approximately $0.5-1 \%$ of world population suffers from this auto-immune disease, with a twofold higher prevalence in women than in men. ${ }^{1,3}$ It is characterized by local destruction of bone and cartilage which can lead to irreversible functional impairment. ${ }^{4}$ Personal, social and economic lives are affected by the disease. It has been reported that mortality in women with RA is two to three fold than in women without RA in the same age. ${ }^{5}$

The cause of RA remains unknown. However, environmental factors as well as genetic factors clearly play a prominent role. ${ }^{1,6}$ Among these environmental factors, infectious pathogens in general and viral infections in particular have been linked to the pathogenesis of RA. ${ }^{7-10}$ Common viruses which infect the worldwide population have

\footnotetext{
1 Corresponding author: Department of Histology Faculty of Medicine Riau University Pekanbaru Indonesia dr_huriatul@yahoo.co.id
}

been proposed to be potential triggers of disease in genetically predisposed individuals. However, it remains difficult to demonstrate a direct link as clinical RA may develop only many years after the primary viral exposure. Epstein - Barr virus (EBV), human endogenous retrovirus-5, human herpes virus-6 (HHV-6), HHV-8, parvo-virus B19 and HTLV-1 have all been implicated in the pathogenesis of RA. ${ }^{11-13}$ Of these, the most convincing data are probably related to EBV infections as, for example, high levels of antibodies against several EBV proteins were detected in sera of RA patients. In this review, we aim to summarize the data linking EBV infection on the immuno-pathogenesis of RA. EBV and its protein which is important in pathogenesis of EBV infection, host immune responses against EBV infection, the autoimmune RA and its pathogenesis will be explained followed by several pro and contra data about the link of EBV infection with RA immunopathogenesis.

\section{EPSTEIN BARR VIRUS}

EBV is a human herpes virus which belongs to the gamma herpes family and infects more than $90 \%$ of the adult population worldwide. The virus can be transferred from one human host to others via 
oral route as the viruses are secreted in the saliva. The main target of the virus is the B lymphocyte, but it can also infect epithelial cells and T cells. ${ }^{14}$ Primary infection with EBV occurs mostly in the first decade of life and is asymptomatic. When primary infection occurs in adulthood, it can lead to a benign, self limiting lymphoproliferative disease which is known as infectious mononucleosis. ${ }^{15}$

EBV is a double stranded DNA virus with a $172 \mathrm{~kb}$ genome. It is a large virus with a molecular weight of $100 \times 10^{6} \mathrm{Da}$. The nucleic acid of the virion is surrounded by an icosahedral capsid, which in turn is surrounded by an irregularly shaped and lipidrich envelope. ${ }^{16}$ EBV's envelope is mainly composed of glycoprotein-350 (gp350), which binds to its receptor complement receptor-2 (CR-2 or CD21) on the surface of B cells or epithelial cells. CR-2 is essential to stimulate humoral immune response against foreign antigens. Normally, this receptor interacts with $\mathrm{C} 3 \mathrm{~d}$, a bioactive fragment of complement protein- 3 on the surface of foreign antigen. This interaction will stimulate the downstream signal which initiates the humoral immune response. In EBV infection, gp350 will bind CR-2 and thereby allow the virus to attach to B cells. Moreover, this will block the interaction of CR-2 with $\mathrm{C} 3 \mathrm{~d}$ and thereby block the initiation of a normal humoral immune response to the pathogen. ${ }^{17-19}$

MHC class II is a cofactor of EBV infection. The interaction of the EBV protein, gp42, with MHC class II, more specifically with HLA-DR, allows the virus to enter the $\mathrm{B}$ cell via membrane fusion..$^{20} \mathrm{In}$ the absence of mature B cell, such as in X-linked agammaglobulinemia patients, EBV is not able to cause an infection either in vivo or in vitro. ${ }^{21}$ Epithelial cells, unlike B-cells, do not express CR2 and HLA-DR; in this cell type, EBV interacts with the cellular target through $\mathrm{gH} / \mathrm{gL} .22,23$

In earlier studies, it has been postulated that EBV replicates in epithelial cells which results in new viral production and lysis of the infected cells. $\mathrm{B}$ cells are secondarily infected by contact with the infected epithelial cells. ${ }^{24}$ Some studies, however, proposed that resting B cells in the oropharynx are the primary cellular target of infection. ${ }^{24,25}$

In the virus, the DNA forms a linear genome encoding nearly 100 viral proteins. These proteins are important for regulating the expression of viral genes, replicating viral DNA, forming virion structural components and modulating host immune response during viral replication. Once the virus infects B cells, DNA transforms into a circular genome and becomes an intact episome in the nuclei of the infected cells. The virus will generally remain inactive in this latent form and can persist as such for many decades. Upon decrease of cellular immune function, such as in immuno-compromised patients, the virus can be reactivated and transform from a latent to a lytic cycle in which the virus replicates, induces cell death and subsequent releases of viral particles. ${ }^{26}$

\section{LATENCY PROTEINS AND RNAS IN EBV- INFECTED B LYMPHOCYTES}

In latently infected B cells in vitro, only 2 to 9 genes are expressed. These genes encode the EBV nuclear antigens EBNA1, EBNA2, EBNA3A, EBNA3B, EBNA3C, EBNA-LP and the latent membrane protein LMP1, LMP2A, and LMP2B. ${ }^{14}$

EBNA1 is characterized by a $20-45 \mathrm{kDa}$ glycine-alanine (Gly-Ala) repeat sequence and is coded by a BamK open reading frame. It binds to the origin of EBV episome. This protein maintains the viral DNA as a circular episome in the infected $B$ cell and thereby contributes to the immortalization of B cells in vitro [16]. The interaction of EBNA1 with the episome is also important for virus DNA replication and its distribution to the daughter cells in proliferating cells. ${ }^{27}$ As EBNA1 is not expressed on the cell surface, it does not induce a cytotoxic $\mathrm{T}$ cell response. ${ }^{28}$

EBNA2 is an $86 \mathrm{kDa}$ protein which is expressed during the primary infection of $\mathrm{B}$ cells. This protein is coded by a BamWYH reading frame. EBNA2 is important for the growth and transformation of $\mathrm{B}$ cells. Furthermore, it upregulates the expression of LMP1 and LMP2A. ${ }^{29}$

EBNA3A, EBNA3B, and EBNA3C are proteins with a molecular weight of $140-180 \mathrm{kDa}$. They are encoded by a BERF open reading frame. These three proteins counteract the action of EBNA2 by inhibition of the transcriptional activation of EBNA2-responsive genes. Among these proteins, only EBNA3A and EBNA3C are necessary for $\mathrm{B}$ cells immortalization. ${ }^{16}$ 
LMP1 is known as an oncogene. Transgenic expression of this gene in mouse B cells lead to the development of lymphomas. ${ }^{30}$ This protein is coded by BNLF1, which is the most abundantly transcribed region of the genome in latently infected $B$ cells. LMP1 induces cellular signaling and activation of the NF-êB pathway. This signaling pathway mimics CD40 signaling (figure2). CD 40 is a transmembrane protein expressed by many cell types including B cells. Its ligand, CD154 or CD40L, is expressed mainly by activated $\mathrm{T}$ cells. The interaction of CD40-CD154 has pivotal role in B cell proliferation and survival, germinal centre formation, Ig isotype switching and generation of memory B cell. By imitating this signal, EBV can maintain their persistent in life time of the host. Moreover, LMP1 also upregulates the expression of the anti-apoptotic proteins BCL2 and A20. . $^{31-33}$

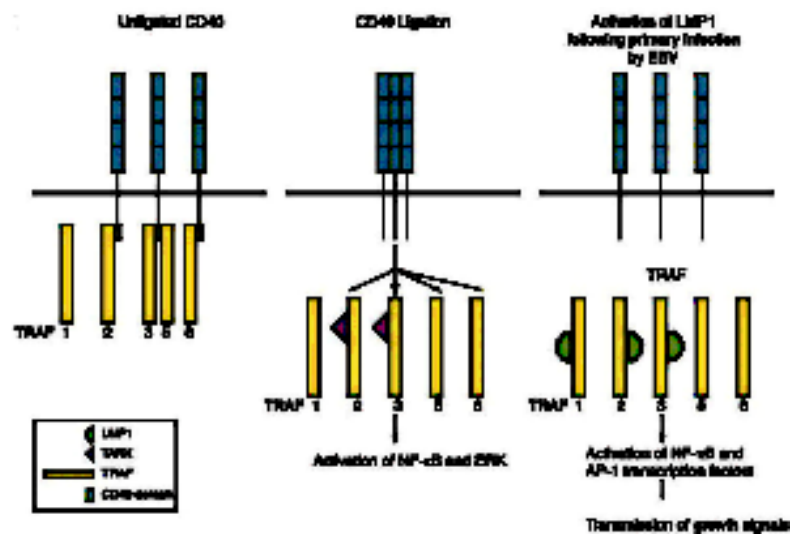

Figure 2. LMP1 mimics CD40-mediated B cell activation via both tumor necrosis factor receptor-associated factor (TRAF) signaling molecule and the transcription factor NF-êB. ${ }^{34}$

LMP2A interferes with B cell receptor (BCR) signaling, a process mediated by the Immunoreceptor Tyrosine-Based Activation Motifs (ITAMs) in its cytoplasmic domain of the BCR associated molecules CD79A and CD79B. In the presence of LMP2A, the tyrosine kinases required for downstream signaling are sequestered, thereby inhibiting BCR signaling. This action will prevent EBV infected B cells to enter the lytic cycle upon antigenic BCR stimulation. In other circumstances, the tyrosine kinases can be stimulated by LMP2A in order to provide crucial survival signals to the B cells (figure 3 ). ${ }^{35}$
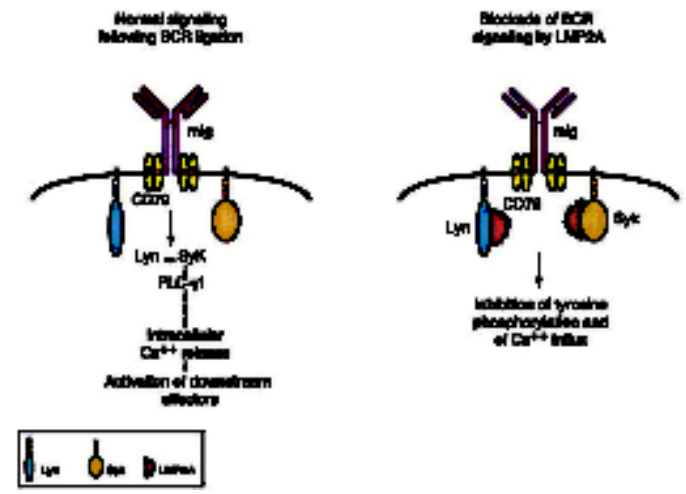

Figure 3. LMP2A inhibits the BCR signaling by sequestering tyrosine kinase from BCR which lead to inhibition of $\mathrm{Ca}^{++}$influx and of downstream effectors activation. ${ }^{34}$

Besides those genes, latently infected B-cells transcribe two types of EBV-encoded nontranslated-RNA: EBV-encoded RNAs (EBERs) and BamH1-A rightwards transcripts (BARTs). EBER1 and EBER2 encode short non-polyadenylated RNAs. They might have important roles in the growth of infected B cells and the suppression of cytotoxic T cells by inducing IL-10 secretion. ${ }^{36}$

\section{HOST IMMUNE RESPONSES AGAINST EBV INFECTION}

Huge numbers of polyclonally expanded B cells are detected in the primary infection. The virus can persist latently in infected memory B cells during the whole life time of human host as it is able to inhibit the apoptosis of the infected cells and to block antiviral effect of IFNã. ${ }^{37}$ The virus is also able to modulate the immune system by up regulating IL- $1 \mathrm{~b}$, TNFa and IL- 6 production ${ }^{38,39}$ and suppressing IL-10 and CSF-1 receptor production. ${ }^{40 \text {, }}$ 41

Antibody against EBV viral capsid antigen (VCA) and early antigen complex-diffuse (EA-D) are detected in early infection. Weeks to months after the first infection, antibody against EBV nuclear antigen (EBNA) and early antigen complexrestricted (EA-D) emerge: anti-EBNA-2 raises first 
and declines within few weeks, followed by increasing titers of anti-EBNA-1 which then persist during the latent infection. Anti-VCA and anti-EA$\mathrm{R}$ IgG will also persist while the corresponding IgM antibodies will decrease to very low or undetectable level (figure 4). ${ }^{16}$

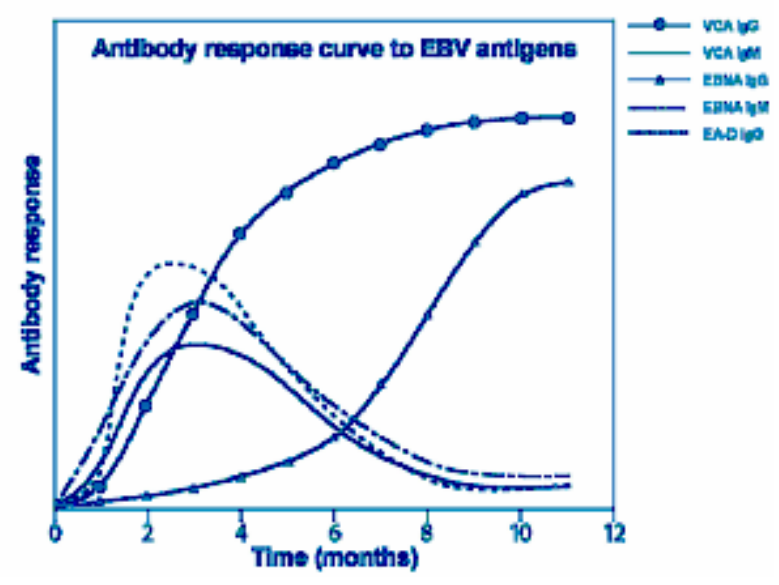

Figure 4. Scheme of antibodies response during EBV infection. ${ }^{15}$

The polyclonal expansion of B cells during primary infection is followed by an increase of CD8+ cytotoxic T lymphocytes specific to lytic viral antigen[42]. EBV-specific CD4+ T cells are also activated during acute infection but the number of these cells does not increase in peripheral blood. ${ }^{43}$ Predominant production of IFNã and IL-2 suggests a T helper 1 profile. ${ }^{44,45}$

\section{RHEUMATOID ARTHRITIS}

The current pathogenesis concept of RA proposes a primary autoimmune process leading to chronic inflammation and subsequent joint destruction. Accordingly, the main targets of RA are the synovial membrane, the cartilage and the bone. The autoimmune origin of RA is supported by the production of antibodies specific against immunoglobulin $\mathrm{G}$ (IgG), which are known as rheumatoid factors (RF), and anti-citrullinated protein antibodies or ACPA. ${ }^{1}$

RF has already been described in the 1930s and their strong association with RA has allowed its use as diagnostic tool. Although it is still not clear whether RF also play a direct pathogenic role, they may be involved in the formation of immune complexes and subsequent activation of complement. However, this does not seem to be sufficient to induce arthritis in experimental models. ${ }^{2}$

ACPA have been discovered more recently. This serum autoreactivity has been known for more than 4 decades as anti-perinuclear factor but the exact molecular basis, reactivity against citrullinated epitopes, has only been described in the late nineties. These autoantibodies recognize protein epitopes that have been modified post-translationally by enzymatic conversion of arginine to citrulline. ${ }^{46}$ Approximately $50-70 \%$ of RA patients and less than $2 \%$ of healthy population are ACPA positive. These autoantibodies are rarely detected in other inflammatory diseases, ${ }^{47,48}$ resulting in a very good diagnostic performance of ACPA. Interestingly, RA patient mostly develop ACPA before the onset of the clinical disease. ${ }^{49}$ Despite some indications in animal models, also here it remains unclear if these autoanibodies are functionally involved in the disease pathogenesis or are merely secondary bystanders. ${ }^{50}$

An autoimmune origin of RA is also supported by the strong genetic association with certain types of HLA-DRB1. HLA-DRB1 has been classified into susceptible, neutral and protective groups. DR1 and DR4 (except DRB 1*0402 and DRB1*0403) subtypes are categorized as the susceptible subtypes. DR3 and DR15 are the neutral subtypes, and DR7, DR8 and DRB1*0402 are the protective subtypes of HLA-DRB $1 .{ }^{51}$ The severity of disease might be influenced by the presence of this so-called shared epitope. Cartilage and bone destruction is also more pronounced in patients with susceptible HLA-DRB1 subtypes. ${ }^{52}$

Environmental contributions such as smoking, microorganisms and stress are also thought to play an important role in RA development. Smoking is well established as one of high risk factors to develop RA, in particular in the presence of HLADR4. Whereas smoking can induce the expression of PAD, the enzyme responsible for citrullination, it remains uncertain if this really leads to specific citrullination of self proteins which subsequently drive pathogenic humoral responses against these autoantigens. ${ }^{2,53}$ On the contrary, the fact that 
smoking is also a risk factor for other autoimmune disease which are not associated with ACPA rather suggests that it has a non-specific adjuvant effect on the autoimmune responses.

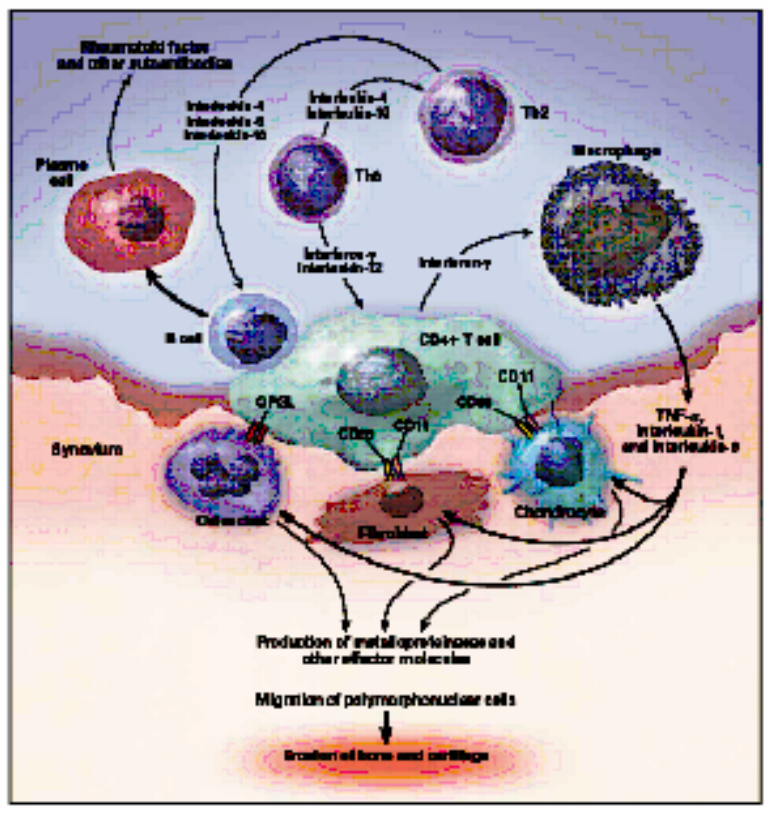

Figure 5. Cellular pathways involved in rheumatoid arthritis. ${ }^{54}$

In RA, the inflamed synovial membrane is characterized by hyperplasia of the synovial lining layer, hypervascularity, and infiltration of the synovial sublining by inflammatory cells, including CD4+ T cells. These CD4+ T-cells might be activated by yet unidentified autoantigens presented by the shared epitope MHC molecules to release IFNã and stimulate monocytes, macrophages and synovial fibroblasts to produce pro-inflammatory cytokines such as IL-1, IL-6 and TNFá. In addition, matrix metalloproteinase production and secretion is activated through cellular signaling mediated by CD69 and CD11. Cell surface contact of activated CD4+ T-cells with B cells or the binding of both cells via á1â2 integrin, CD154 (CD40 ligand) and CD28 interaction will stimulate $\mathrm{B}$ cells to produce immunoglobulins, including rheumatoid factors. Furthermore, the expression of RANK ligand on activated $\mathrm{CD} 4+\mathrm{T}$ cells will stimulate osteoclastogenesis (figure 5). ${ }^{54}$

\section{THE LINK OF EBV INFECTION WITH THE IMMUNOPATHOGENESIS OF RHEUMATOID ARTHRITIS}

EBV has been proposed as one the environmental triggers for RA since many years. One of the favorite hypotheses to explain this link relates to molecular mimicry. Indeed, EBV glycoprotein gp110 (BALF4) contains a peptide sequence (QKRAA) which is completely homologue with the previously discussed shared epitope of specific susceptible alleles for RA. ${ }^{55}$ This protein can be found in huge amounts during the late lytic phase of EBV infection and plays a role in the replication cycle of the virus. It is also the target of antibody dependent cell-mediated cytotoxicity against EBV infected cells. Supporting the molecular mimicry hypothesis, the carriers of those genes have higher risk to develop RA triggered by EBV infection. ${ }^{56,57}$ Moreover, BOLF1, which serves as viral tegument protein and BALF2, the major viral DNA-binding protein, also contain homologue sequences with HLA-DRB1 allele epitopes and seem to play a role in juvenile arthritis pathogenesis. $^{58}$

An alternative hypothesis proposes crossreactive antibodies as potential link between EBV and RA. Antibodies directed against nuclear antigen of EBV transformed B cells have been detected in the sera of RA patients. The antigen known as rheumatoid arthritis nuclear antigen (RANA) is similar to EBNA-1. ${ }^{59}$ Anti-RANA antibodies recognize an epitope from the glycine/alanin repetitive sequence of EBNA-1. These antibodies are cross-reactive with a $62 \mathrm{kDa}$ protein which exists in RA synovium and did not show any reactivity towards non-RA synovium. ${ }^{60-62}$

A third hypothesis proposes that the EBV viral load is higher in RA patients. An in vitro study on peripheral blood of RA patients showed that the susceptible HLA-DRB $1 * 0404$ correlated with low frequencies of EBV gp110-specific T cell precursors whereas HLA-DRB*07, which has a protective effect for developing RA, was associated with high frequencies of EBV gp-110 specific T cell precursors. ${ }^{63}$ Furthermore, quantification using realtime polymerase chain reaction (RT-PCR) showed that the EBV DNA load was significantly increased in RA compared to normal controls. ${ }^{64,65}$ However, 
this study showed no differences in viral load between HLA-DR susceptible and protective alleles. ${ }^{64}$ Moreover, a more recent study indicated that there was an increase in $\mathrm{RA}$ of $\mathrm{CD} 8+\mathrm{T}$ cell as well as $\mathrm{B}$ cell responses to pooled lytic and latent EBV antigens which are involved in B cell transformation and viral replication. There was a correlation between viral load in circulating blood cells and the increase of EBV-specific and IFNãproducing $\mathrm{CD} 8+\mathrm{T}$ cells, without evidence for defective $\mathrm{T}$ cell control of the EBV infection. ${ }^{66}$ Although the results on $T$ cell responses thus appear to be discrepant, there is clear evidence from these studies for a higher viral load in RA.

An alternative explanation for the higher viral load may relate to B lymphocytes. As discussed, $\mathrm{EBV}$ can drive the activation and proliferation of $\mathrm{B}$ cells followed by homing of these B cells to the germinal centre, the key anatomic site for maturation of the B cell response as well as for the elimination of detrimental autoreactivity. The virus will reside in these cells by silencing all EBV proteins except EBNA1. ${ }^{67}$ In RA patients, it has been shown that there is a defect in memory B cell tolerance mechanism which can lead to the enhancement of circulating autoreactive B-cells and secreted autoantibodies such as rheumatoid factors. On the other hand, it has been reported that RF could induce EBV replication through BCR stimulation in vitro. ${ }^{68,69}$ The frequent recognition of autoantigen by RF+ B cells in RA could be the other explanation of higher viral load instead of defective T-cell control of EBV infection.

Despite the increased viral load in peripheral blood, there is still no consensus on the expression of EBV in synovial tissue, the primary site of inflammation in RA. Blaschke et al reported that the viral load in synovial fluid cells was higher in RA patients than normal controls. ${ }^{65}$ Bokarewa et al found that both synovial fluid and peripheral blood dsRNA levels were significantly higher in RA than in osteoarthritis. The detection of dsRNA in synovial fluid is an indication of the existence of local viral nucleic acids. From 17 RA patients, EBV was detected in 7 patients and no parvovirus, CMV and polyomavirus were detected..$^{70}$ In a follow-up study, the same group found that viral dsRNA is highly arithrogenic in mice suggesting that dsRNA in synovial fluid of RA may be related to the erosive disease. ${ }^{71}$
An extremely high viral load in synovial tissue was reported by Saal et al. They detected EBV DNA more frequently in RA synovium than non-RA synovium by using PCR analysis. ${ }^{57}$ Takeda et al reported the same findings and in addition quantified EBV copy numbers in each sample. They found more than 1 EBV DNA copy per 1000 cells in 9 of 32 RA synovial samples. They also could detect EBV in 3 RA synovial samples by using southern blot assay, which is less sensitive to detect DNA than PCR. Furthermore, BZLF1 and gp350/220, which are expressed in lytic state of EBV infection, were detected in synovial tissue of RA by immunohistochemistry. ${ }^{72}$ The latter investigation supports the report by Scotet et al showing that a large fraction of CD8+ T cells infiltrating the inflamed joint in RA recognize both lytic antigens BZLF1 and BMLF1. ${ }^{73}$ It was also reported that synovial lining cells were infected by EBV by using in situ hybridization for detection of EBERs, the most sensitive markers of latent EBV infection. ${ }^{74}$ In contrast, however, Niedobitek et al reported that they could not detect the existence of EBV infection in synovial lining cells by using in situ hybridization. Improvement of their technique by using ${ }^{35} \mathrm{~S}$-labeled EBER specific probes only showed weak EBER detection in 7 of 37 RA patients. They also could not detect the expression of LMP1 and BZLF1 in synovial lining cells and lymphocytes of RA synovial tissue..$^{75}$ These results are concordant with what was found by Mousavi-Jazi et al. This group could detect EBV DNA in only 2 of 31synovial tissue samples of RA patients by PCR. ${ }^{76}$ Taken together, it is not yet completely clear whether EBV is really present in the inflamed synovium and, if yes, whether this presence is increased in RA compared to other types of arthritis.

A fourth hypothesis has recently been proposed to explain the relation between EBV and RA. It was demonstrated that viral peptides, and in particular EBNA-1 ${ }^{35-38}$, can contain Gly-Arg repeats in which arginine is replaced by citrulline. Antibodies against this viral antigen (viral citrullinated peptide of VCP) were significantly higher in RA sera than healthy controls. Furthermore, affinity-purified anti-VCP antibodies from RA sera were reactive against deiminated recombinant EBNA-1 as well as filaggrin-derived citrulline peptides. ${ }^{77}$ These data suggest that EBV might be able to induce ACPA 
production in RA patients.

At last, the capability of EBV mimics CD40 signaling via the latent protein LMP1 proposes its relation to RA. CD40-CD40L interaction is crucial for EBV to maintain their persistent in the host memory B cells [33]. However the interaction might also induce the production of immunoglobulin including rheumatoid factors. ${ }^{54}$ Indeed, the susceptibility and severity of RA is higher in the present of EBV than in the absent of this virus.

\section{CONCLUSIONS}

In conclusion, there is a clear link between EBV infection and RA pathogenesis but the exact cellular and molecular pathways explaining this link remain unclear. It may relate to a bystander 'adjuvant' effect of the viral infection, to molecular mimicry of EBV with shared epitope, to manipulation of $\mathrm{B}$ cell tolerance by EBV, or to specific citrullination processes spreading from an anti-viral to an autoimmune response. Two major hurdles to study these processes are that $1 /$ more than $90 \%$ of the adult population has been infected with EBV and thus that it remains challenging to compare EBV positive and EBV negative RA patients, and 2/ that EBV only affects primates, excluding to study of the link between EBV and RA in rodent models.

\section{REFERENCES}

1. Firestein, G.S., Evolving concepts of rheumatoid arthritis. Nature, 2003. 423(6937): p. 356-61.

2. Klareskog,L., et al., Genes, environment and immunity in the development of rheumatoid arthritis. Curr Opin Immunol, 2006. 18(6): p. 650-5.

3. Symmons, D.P., et al., The incidence of rheumatoid arthritis in the United Kingdom: results from the Norfolk Arthritis Register. $\mathrm{Br} \mathrm{J}$ Rheumatol, 1994. 33(8): p. 735-9.

4. Arnett, F.C., et al., The American Rheumatism Association 1987 revised criteria for the classification of rheumatoid arthritis. Arthritis Rheum, 1988. 31(3): p. 315-24.

5. Wolfe, F., et al., The mortality of rheumatoid arthritis. Arthritis Rheum, 1994. 37(4): p. 48194.
6. Balandraud, N., J. Roudier, and C. Roudier, Epstein-Barr virus and rheumatoid arthritis. Autoimmun Rev, 2004. 3(5): p. 362-7.

7. Albert, L.J. and R.D. Inman, Molecular mimicry and autoimmunity. N Engl J Med, 1999. 341(27): p. 2068-74.

8. Bonneville, M., et al., Epstein-Barr virus and rheumatoid arthritis. Rev Rhum Engl Ed, 1998. 65(6): p. 365-8.

9. Carty, S.M., N. Snowden, and A.J. Silman, Should infection still be considered as the most likely triggering factor for rheumatoid arthritis? J Rheumatol, 2003. 30(3): p. 425-9.

10.Masuko-Hongo, K., T. Kato, and K. Nishioka, Virus-associated arthritis. Best Pract Res Clin Rheumatol, 2003. 17(2): p. 309-18.

11.Kerr, J.R., Pathogenesis of human parvovirus B19 in rheumatic disease. Ann Rheum Dis, 2000. 59(9): p. 672-83.

12.Newkirk, M.M., et al., Detection of cytomegalovirus, Epstein-Barr virus and herpes virus-6 in patients with rheumatoid arthritis with or without Sjogren's syndrome. Br J Rheumatol, 1994. 33(4): p. 317-22.

13.Zhang, L., et al., Detection of herpesviruses by polymerase chain reaction in lymphocytes from patients with rheumatoid arthritis. Arthritis Rheum, 1993. 36(8): p. 1080-6.

14.Rickinson, A.B., Kieff, E., Epstein Barr Virus, in Fields Virology. 2001, Lippincott-Raven Philadelphia: Knipe, D.M. \& Howley, P.M. p. 2575-2672

15.Jenson, H.B., Acute Epstein Barr Virus infections. Bailliere's Clin. Infect. Dis, 1996. 3: p. 477-506.

16.Crawford, D.H., Principle and Practise of Clinical Virology 5th edition. 2004: John Wiley \& Sons, Ltd.

17.Guthridge, J.M., et al., Epitope mapping using the $X$-ray crystallographic structure of complement receptor type 2 (CR2)/CD21: identification of a highly inhibitory monoclonal antibody that directly recognizes the CR2-C3d interface. J Immunol, 2001. 167(10): p. 575866. 
18.Sarrias, M.R., et al., Kinetic analysis of the interactions of complement receptor 2 (CR2, $C D 21)$ with its ligands $C 3 d, i C 3 b$, and the $E B V$ glycoprotein gp350/220. J Immunol, 2001. 167(3): p. 1490-9.

19.Szakonyi, G., et al., Structure of complement receptor 2 in complex with its C3d ligand. Science, 2001. 292(5522): p. 1725-8.

20.Mullen, M.M., et al., Structure of the EpsteinBarr virus gp 42 protein bound to the MHC class II receptor HLA-DR1. Mol Cell, 2002. 9(2): p. $375-85$.

21.Faulkner, G.C., et al., $X$-Linked agammaglobulinemia patients are not infected with Epstein-Barr virus: implications for the biology of the virus. J Virol, 1999. 73(2): p. 155564.

22.Molesworth, S.J., et al., Epstein-Barr virus $g H$ is essential for penetration of $B$ cells but also plays a role in attachment of virus to epithelial cells. J Virol, 2000. 74(14): p. 6324-32.

23.Farrell, P.J., Cell-switching and kissing. Nat Med, 2002. 8(6): p. 559-60.

24.Sixbey, J.W., et al., Replication of Epstein-Barr virus in human epithelial cells infected in vitro. Nature, 1983. 306(5942): p. 480-3.

25.Niedobitek, G., et al., Epstein-Barr virus (EBV) infection in infectious mononucleosis: virus latency, replication and phenotype of $E B V$ infected cells. J Pathol, 1997. 182(2): p. 151-9.

26.Kuppers, R., B cells under influence: transformation of $B$ cells by Epstein-Barr virus. Nat Rev Immunol, 2003. 3(10): p. 801-12.

27. Yates, J.L., N. Warren, and B. Sugden, Stable replication of plasmids derived from EpsteinBarr virus in various mammalian cells. Nature, 1985. 313(6005): p. 812-5.

28.Levitskaya, J., et al., Inhibition of antigen processing by the internal repeat region of the Epstein-Barr virus nuclear antigen-1. Nature, 1995. 375(6533): p. 685-8.

29.Johannsen, E., et al., Epstein-Barr virus nuclear protein 2 transactivation of the latent membrane protein 1 promoter is mediated by J kappa and PU.1. J Virol, 1995. 69(1): p. 253-62.
30.Kulwichit, W., et al., Expression of the EpsteinBarr virus latent membrane protein 1 induces $B$ cell lymphoma in transgenic mice. Proc Natl Acad Sci U S A, 1998. 95(20): p. 11963-8.

31.Bishop, G.A. and B.S. Hostager, The CD40CD154 interaction in B cell-T cell liaisons. Cytokine Growth Factor Rev, 2003. 14(3-4): p. 297-309.

32.Brown, K.D., B.S. Hostager, and G.A. Bishop, Differential signaling and tumor necrosis factor receptor-associated factor (TRAF) degradation mediated by CD4O and the Epstein-Barr virus oncoprotein latent membrane protein 1 (LMP1). J Exp Med, 2001. 193(8): p. 943-54.

33.Kilger, E., et al., Epstein-Barr virus-mediated $B$-cell proliferation is dependent upon latent membrane protein 1 , which simulates an activated CD40 receptor. EMBO J, 1998. 17(6): p. 1700-9.

34.Hasler, P. and M. Zouali, Subversion of B lymphocyte signaling by infectious agents. Genes Immun, 2003. 4(2): p. 95-103.

35.Merchant, M., et al., The effects of the EpsteinBarr virus latent membrane protein $2 A$ on $B$ cell function. Int Rev Immunol, 2001. 20(6): p. 80535.

36. Kitagawa, N., et al., Epstein-Barr virus-encoded poly $(A)(-)$ RNA supports Burkitt's lymphoma growth through interleukin-10 induction. EMBO J, 2000. 19(24): p. 6742-50.

37.Cohen, J.I., Epstein-Barr virus infection. N Engl J Med, 2000. 343(7): p. 481-92.

38.D'Addario, M., et al., Binding of the EpsteinBarr virus major envelope glycoprotein gp350 results in the upregulation of the TNF-alpha gene expression in monocytic cells via NF-kappaB involving PKC, PI3-K and tyrosine kinases. $\mathrm{J}$ Mol Biol, 2000. 298(5): p. 765-78.

39.D'Addario, M., et al., Epstein-Barr virus envelope glycoprotein gp350 induces NFkappaB activation and IL-1beta synthesis in human monocytes-macrophages involving $P K C$ and PI3-K. FASEB J, 1999. 13(15): p. 2203-13.

40.Cohen, J.I. and K. Lekstrom, Epstein-Barr virus $B A R F 1$ protein is dispensable for $B$-cell 
Huriatul Masdar, The Link Of Epstein Barr Virus Infection And Rheumatoid Arthritis Immunopathogenesis

transformation and inhibits alpha interferon secretion from mononuclear cells. J Virol, 1999. 73(9): p. 7627-32.

41.Hsu, D.H., et al., Expression of interleukin-10 activity by Epstein-Barr virus protein BCRF1. Science, 1990. 250(4982): p. 830-2.

42.Callan, M.F., et al., Large clonal expansions of CD8+ T cells in acute infectious mononucleosis. Nat Med, 1996. 2(8): p. 906-11.

43.Williams, H., et al., Analysis of immune activation and clinical events in acute infectious mononucleosis. J Infect Dis, 2004. 190(1): p. 6371.

44.Attarbaschi, T., et al., $T$ cell cytokine profile during primary Epstein-Barr virus infection (infectious mononucleosis). Eur Cytokine Netw, 2003. 14(1): p. 34-9.

45.Corsi, M.M., et al., High Thl-type cytokine serum levels in patients with infectious mononucleosis. Acta Virol, 2004. 48(4): p. 2636.

46.Schellekens, G.A., et al., Citrulline is an essential constituent of antigenic determinants recognized by rheumatoid arthritis-specific autoantibodies. J Clin Invest, 1998. 101(1): p. 273-81.

47.Kastbom, A., et al., Anti-CCP antibody test predicts the disease course during 3 years in early rheumatoid arthritis (the Swedish TIRA project). Ann Rheum Dis, 2004. 63(9): p. 10859.

48.Ronnelid, J., et al., Longitudinal analysis of citrullinated protein/peptide antibodies (anti$C P$ ) during 5 year follow up in early rheumatoid arthritis: anti-CP status predicts worse disease activity and greater radiological progression. Ann Rheum Dis, 2005. 64(12): p. 1744-9.

49.Nielen, M.M., et al., Specific autoantibodies precede the symptoms of rheumatoid arthritis: a study of serial measurements in blood donors. Arthritis Rheum, 2004. 50(2): p. 380-6.

50.Lundberg, K., et al., Citrullinated proteins have increased immunogenicity and arthritogenicity and their presence in arthritic joints correlates with disease severity. Arthritis Res Ther, 2005. 7(3): p. R458-67.
51.Reviron, D., et al., Influence of shared epitopenegative HLA-DRB1 alleles on genetic susceptibility to rheumatoid arthritis. Arthritis Rheum, 2001. 44(3): p. 535-40.

52. Weyand, C.M., et al., The influence of HLADRB1 genes on disease severity in rheumatoid arthritis. Ann Intern Med, 1992. 117(10): p. 8016.

53. Klareskog, L., L. Padyukov, and L. Alfredsson, Smoking as a trigger for inflammatory rheumatic diseases. Curr Opin Rheumatol, 2007. 19(1): p. 49-54.

54.Choy, E.H. and G.S. Panayi, Cytokine pathways and joint inflammation in rheumatoid arthritis. N Engl J Med, 2001. 344(12): p. 907-16.

55.Gregersen, P.K., J. Silver, and R.J. Winchester, The shared epitope hypothesis. An approach to understanding the molecular genetics of susceptibility to rheumatoid arthritis. Arthritis Rheum, 1987. 30(11): p. 1205-13.

56.Jilg, W., et al., The Epstein-Barr virus-encoded glycoprotein gp 110 (BALF 4) can serve as a target for antibody-dependent cell-mediated cytotoxicity (ADCC). Virology, 1994. 202(2): p. 974-7.

57.Saal, J.G., et al., Synovial Epstein-Barr virus infection increases the risk of rheumatoid arthritis in individuals with the shared HLA-DR4 epitope. Arthritis Rheum, 1999. 42(7): p. 148596.

58. Massa, M., et al., Proinflammatory responses to self HLA epitopes are triggered by molecular mimicry to Epstein-Barr virus proteins in oligoarticular juvenile idiopathic arthritis. Arthritis Rheum, 2002. 46(10): p. 2721-9.

59.Alspaugh, M.A., et al., Elevated levels of antibodies to Epstein-Barr virus antigens in sera and synovial fluids of patients with rheumatoid arthritis. J Clin Invest, 1981. 67(4): p. 1134-40.

60.Fox, R., et al., Rheumatoid arthritis synovial membrane contains a 62,000-molecular-weight protein that shares an antigenic epitope with the Epstein-Barr virus-encoded associated nuclear antigen. J Clin Invest, 1986. 77(5): p. 1539-47.

61.Venables, P.J., et al., Reaction of antibodies to 
rheumatoid arthritis nuclear antigen with a synthetic peptide corresponding to part of Epstein-Barr nuclear antigen 1. Ann Rheum Dis, 1988. 47(4): p. 270-9.

62.Rumpold, H., et al., The glycine-alanine repeating region is the major epitope of the Epstein-Barr nuclear antigen-1 (EBNA-1). J Immunol, 1987. 138(2): p. 593-9.

63.Toussirot, E., et al., Decreased T cell precursor frequencies to Epstein-Barr virus glycoprotein Gp110 in peripheral blood correlate with disease activity and severity in patients with rheumatoid arthritis. Ann Rheum Dis, 2000. 59(7): p. 5338.

64.Balandraud, N., et al., Epstein-Barr virus load in the peripheral blood of patients with rheumatoid arthritis: accurate quantification using real-time polymerase chain reaction. Arthritis Rheum, 2003. 48(5): p. 1223-8.

65.Blaschke, S., et al., Epstein-Barr virus infection in peripheral blood mononuclear cells, synovial fluid cells, and synovial membranes of patients with rheumatoid arthritis. J Rheumatol, 2000. 27(4): p. 866-73.

66.Lunemann, J.D., et al., Increased frequency of EBV-specific effector memory CD8+T cells correlates with higher viral load in rheumatoid arthritis. J Immunol, 2008. 181(2): p. 991-1000.

67.Hochberg, D., et al., Demonstration of the Burkitt's lymphoma Epstein-Barr virus phenotype in dividing latently infected memory cells in vivo. Proc Natl Acad Sci U S A, 2004. 101(1): p. 239-44.

68.Scofield, R.H., Autoantibodies as predictors of disease. Lancet, 2004. 363(9420): p. 1544-6.
69. Yang, L., et al., Rheumatoid factors induce signaling from B cells, leading to Epstein-Barr virus and B-cell activation. J Virol, 2004. 78(18): p. 9918-23.

70.Bokarewa, M., et al., Arthritogenic dsRNA is present in synovial fluid from rheumatoid arthritis patients with an erosive disease course. Eur J Immunol, 2008. 38(11): p. 3237-44.

71.Zare, F., et al., Arthritogenic properties of double-stranded (viral) RNA. J Immunol, 2004. 172(9): p. 5656-63.

72.Takeda, T., et al., Lytic Epstein-Barr virus infection in the synovial tissue of patients with rheumatoid arthritis. Arthritis Rheum, 2000. 43(6): p. 1218-25.

73. Scotet, E., et al., T cell response to Epstein-Barr virus transactivators in chronic rheumatoid arthritis. J Exp Med, 1996. 184(5): p. 1791-800.

74.Takei, M., et al., Detection of Epstein-Barr virusencoded small RNA 1 and latent membrane protein 1 in synovial lining cells from rheumatoid arthritis patients. Int Immunol, 1997. 9(5): p. 739-43.

75.Niedobitek, G., et al., Lack of evidence for an involvement of Epstein-Barr virus infection of synovial membranes in the pathogenesis of rheumatoid arthritis. Arthritis Rheum, 2000. 43(1): p. 151-4.

76.Mousavi-Jazi, M., et al., Infrequent detection of cytomegalovirus and Epstein-Barr virus DNA in synovial membrane of patients with rheumatoid arthritis. J Rheumatol, 1998. 25(4): p. 623-8.

77.Pratesi, F., et al., Deiminated Epstein-Barr virus nuclear antigen 1 is a target of anti-citrullinated protein antibodies in rheumatoid arthritis. Arthritis Rheum, 2006. 54(3): p. 733-41. 